\title{
Time as Experience/Experience as Temporality
}

Pragmatic and Perfectionist Reflections on Extemporaneous Creativity

\section{Vincent Colapietro}

\section{(2) OpenEdition Journals}

Electronic version

URL: http://journals.openedition.org/ejpap/594

DOI: 10.4000/ejpap.594

ISSN: 2036-4091

Publisher

Associazione Pragma

\section{Electronic reference}

Vincent Colapietro, "Time as Experience/Experience as Temporality », European Journal of Pragmatism and American Philosophy [Online], V-1 | 2013, Online since 16 July 2013, connection on 21 April 2019

URL : http://journals.openedition.org/ejpap/594 ; DOI : 10.4000/ejpap.594

This text was automatically generated on 21 April 2019

\section{(c) (1) $\odot$}

Author retains copyright and grants the European Journal of Pragmatism and American Philosophy right of first publication with the work simultaneously licensed under a Creative Commons Attribution-

NonCommercial-NoDerivatives 4.0 International License. 


\title{
Time as Experience/Experience as Temporality
}

Pragmatic and Perfectionist Reflections on Extemporaneous Creativity

\author{
Vincent Colapietro
}

\section{Introduction: The Experience of Improvisation/The Renovation of Experience}

1 My ultimate goal ${ }^{1}$ is to sketch the broad outlines of an experiential approach to extemporaneous creativity, especially as such creativity is exemplified by jazz musicians. This approach is, at once, pragmatist and (in Stanley Cavell's sense) perfectionist. ${ }^{2}$ But my initial goal is to illuminate human creativity in its less manifest forms.

Paradoxically, such creativity is commonplace. The actions, gestures, and utterances of human beings in everyday life are far from mindless routines. To some extent, they are almost always creative responses to dramatic situations (cf. Joas 1996, Ch. 3). They are, at the very least, unrehearsed responses, that is, improvised or extemporaneous ones. As R. W. Emerson stresses in "Quotation and Originality," they ineluctably draw upon past exertions; they deeply draw upon interiorized traditions. ${ }^{3}$ But the nuanced spontaneity of these extemporaneous exertions ordinarily transcends the mechanical re-enactment of fixed habits. Even a frequently repeated expression, one reiterated innumerable times such as "Hello" or "Good morning," can be variously inflected and by the truly courteous person is situationally modulated. The phrasing of such a person can arguably be as deft as that of Frank Sinatra when shaping a musical phrase (Iseminger 2010: 299). Without question, deeply sedimented habits make possible extemporaneous creativity, so much so that it is easy to allow the operation of such habits to eclipse our appreciation or even awareness of the creativity inherent in our unrehearsed exertions. The innate intelligence of the human animal, precisely as a meshwork of dispositions, is, however, an organ of novelty, all the more so human intelligence in its more mature form. ${ }^{4}$ Such intelligence is as much as anything else a capacity to act creatively (Emerson; Whitehead). 
Present action is, to repeat, not simply the mechanical re-enactment of established dispositions; rather it tends to be an innovative manner of responding to the immanent demands of an unfolding drama. The roots of it in the past should not obscure from us the fruits just now forming themselves in the ever present spring of the living present (CP 5.459; also EP 2: 358). The spontaneity and plasticity of the child can be preserved by or, to some extent, recovered by, the adult. As much as action reveals the presence of habits, it can also alter the form of those habits, if only in subtle and virtually imperceptible ways. Habits owe not only their origin but also their continuance and integration to actions. Our experience of improvisation discloses the irreducible reality of extemporaneity but also the inescapable renovation of experience itself. We are continuously making something of our experience and, therein, re-making nothing less than our selves. What is imperceptibly pervasive in our everyday doings, is dramatically operative in jazz improvisation. In their most successful improvisations, jazz musicians combine the spontaneity of the novice explorer and the control of the experienced practitioner. They draw upon wide and deep experience in order (as much as anything else) to interrogate what their experience prompts them to play. Accordingly, jazz improvisation is a series of focused self-interrogations, a form of exploration in which previously successful modes of exploration are themselves subjected to interrogation. It aims at "a cultivated naiveté of eye, ear, and thought" (LW 1: 40); put otherwise, it culminates in deliberate spontaneity (spontaneity resulting from reflection). The original spontaneity of the very young child and the irrepressible extemporaneity of human actors in the variable scenes of their quotidian engagements are in complex ways related to the cultivated naiveté of the experienced improviser.

3 My goal here is, at the very least, to render this claim plausible. Because not only the acquisition but also the interrogation of experience is so critical in such improvisation, the realization of this goal requires me to embed this sketch in a thick account of human experience. For this, Stanley Cavell no less than the classical pragmatists is critical. Accordingly, the path to the topic of improvisation cannot avoid being somewhat circuitous: it will weave its way through an extended discussion of philosophical appeals to human experience. But the point of this discussion is to underscore the importance of experience itself, not our efforts to articulate a theory of experience. That is, the appeal to experience refers here to what a practitioner does in the context of some engagement; in particular, it refers, in the first instance, to what everyday actors do in the ordinary circumstances of their lives and, in the end, to what jazz musicians do in the context of performance. As this suggests, I am guided by the intuition that musical improvisation is not an utterly unique phenomenon; it is rather part of a vastly extended family of human activity. Therefore, the main reason why I approach our topic in this manner is what William Day suggests in a very instructive treatment of the elusive topic of jazz improvisation: we properly orient ourselves to jazz improvisation (thus, to arguably the most important form of musical creativity) when we strive "to experience improvised music as a species of ordinary, unrehearsed activity" (2000: 102; emphasis added). The experience in question calls for understanding how it relates to both the most commonplace experiences and (to a less extent) other forms of human engagement (e.g., scientific investigation, moral deliberation, and religious worship). First and foremost, however, we need to experience this form of musicking ${ }^{5}$ as a creative refinement of our everyday extemporaneity. The reconstruction of experience advocated by the pragmatists and the approach exemplified by Cavell are undertaken for the sake of enhancing experience itself (Colapietro 2008: 118-19). That is, they are offered as ways of 
rendering our modes of engagement more luminous, intense, fulfilling, significant, and sustainable than they otherwise would be (cf. LW 1: 305). They concern primarily direct (or "immediate") experience itself, not a formal understanding, certainly not a detached understanding, much less an elaborate theory of it. While reading a text is, in this context, one such mode of engagement, so too are watching a film, conversing with a friend, walking around a city, and hiking up a mountain. Their concern is with the quality of the experience of reading, watching, walking, conversing, and climbing. In the end, solicitude for this quality encompasses nothing less than what H. D. Thoreau in Wild Fruits, a recently discovered manuscript, calls the "art of how to spend a day" (Thoreau 2001; cf. Emerson's "Art"). But we also need to articulate an understanding of experience that is able to make sense of what experience actually is in our lives, not only in our formally reflective engagements but also in the myriad contexts of our everyday lives. Philosophical theories of human experience have tended to be crude caricatures, not least of all because they have occluded the most salient features of human experience when experience is considered in reference to the actual achievements and inevitable failures of an experienced practitioner (say, an experienced equestrian or an experienced musician). Hence, part of the task here is to bring into focus the features that other accounts of experience tend to occlude.

The significance of our experience is far greater than the role played by experience in the acquisition of knowledge. ${ }^{6}$ This role is tremendously important and, thus, needs to be properly understood (cf. Haack 2009; also Short 2008). But the appeal to experience is not limited to the differential perspective of the theoretical inquirer (Smith 1981); indeed, it is present in every domain of human engagement. For example, the novice reader might greatly benefit from an experienced one. ${ }^{7}$ The experience of novices is however not to be slighted, certainly not to be denigrated. ${ }^{8}$ Regardless of the practice or site of engagement, it all comes down to "experience personally conducted and personally consummated" (MW 3: 94). But the dominant traditions of Western philosophy are, in effect, so many betrayals of experience, most of all because they assume that, in order for us to comport ourselves responsibly, we must have resources and criteria beyond anything experience could provide. Experience is judged to be, even by Kant and Hegel, not sufficient unto itself. Though Kant and indeed all of the rationalists concede that appeals to experience are in some instances necessary, they are far from sufficient: a transcendental or dialectical or some other form of reason alone can make up for the inherent deficiencies of our finite experience. The need to go beyond experience indeed seems to many thinkers to be an exigency rooted in experience itself. But the classical pragmatists in their way and Cavell in his suggest that the need is rather to turn toward experience in a more painstaking, courageous, and imaginative manner than philosophers have yet done. They do not presume that a trans-experiential reason is required; rather they contend that the cultivated capacities of the human animal are sufficient for drawing from experience what such an animal needs to act responsibly and, indeed, to live wisely.

While the experience of time as experience, ${ }^{9}$ especially as it is exhibited in the extemporaneous creativity of jazz musicians, is our ultimate concern, the appeal to experience is our inaugural topic. Though I will begin by framing this topic with the help of the pragmatists and an exemplary expositor of the pragmatic tradition, I will turn decisively to Cavell's insistence upon the need for "checking one's experience" (1981: 12; cf. Day 2000: 100). That is, we need simultaneously to consult and interrogate our own experience, to fall back upon it and to turn it upon itself. This experiential task is itself a 
prefiguration of extemporaneous creativity. Consequently, in exploring the contours of this task, we will be foreshadowing the exploration of jazz improvisations as an arresting instance of what a reflective engagement with human experience demands.

6 The characteristic focus of human agents is on the most immediately imminent future, the future as it just now is taking shape in the present (see e.g. Peirce: EP 2, 358 and James: MT, 231). Experience is, among other things, a name for what equips the human animal to meet effectively the promptings, pressures, and propulsions of this intimately imminent future (see, e.g., LW 10: 28; also Whitehead 1933 [1961], Ch. XI). The appeal to experience in its rudimentary form is not a formal, articulated appeal; it is rather a spontaneous, situated response, for when agents respond in this manner they are drawing upon (or going ${ }^{10}{ }^{10}$ ) their experience. Even so, the philosophical attempts to accredit the appeal to experience, especially those of the classical pragmatists and Stanley Cavell, help us to understand what is entailed - and indeed entangled - in its most rudimentary form.

\section{The Appeal to Experience: Naïve and Critical}

7 John E. Smith was fond of remarking that William James "wrote as though one had only to consult 'experience' as one consults a timetable in order to find the answer" (Smith 1983: 40). ${ }^{11}$ This is no doubt a caricature. It is, indeed, an intentional one. But there is value in caricaturing James in this manner. For it underscores the difficulties inherent in any appeal to experience. Of course, James was alert to these difficulties and, moreover, Smith was appreciative of James's sensitivity in this regard. But James's efforts to recover experience in a fuller and deeper way than had yet been done occasionally forced him to simplify what is involved in any appeal to experience. A reliable timetable is, of course, the result of a painstaking distillation of controlled observation. As such, it is at a significant distance from primary experience in the Deweyan sense (certainly even farther from "pure" experience in the Jamesian sense!). Such a symbolic chart is at once the reflective distillation from, and a valuable instrument for, ascertaining practical opportunities concerning (say) railroad travel. In a sense, the experience of any mature person is to some extent always already codified. Aye, there's the rub, especially from a Jamesian perspective. So, the appeal to one's own experience is quite unlike that to a timetable.

8 We need not only to appeal to experience but also to reflect on what is entailed when practitioners do so, especially in the context of practice, that is, of performance. So, the necessity of such an appeal cannot be gainsaid, at least by those of us who take experimental science seriously, also by those who consider personal experience uniquely valuable. The very possibility of such an appeal is, however, deeply problematic. If human experience is what traditional philosophy has claimed, it cannot bear the weight or fulfill the functions placed upon it. The recovery of experience must, at least in part, be a reconstruction of our understanding of experience such that experience can bear, for example, the weight of experimental evidence, as this expression is used by the scientific inquirer, or that of personal testimony, as this is understood in a historical situation. Even so, it cannot be merely a reconstruction of our understanding of experience, for it must be both a creative appropriation and an ongoing transformation of our actual experience (Colapietro 2008). In other words, it must be an enhancement of experience itself, an enhancement due above all else to the cumulative effects of making our 
experience, at once, more our own and more trust- worthy. The appeal to experience is something we do; and that to which we appeal is, in some manner and measure, called into being as the result of our appeals. Experience is, in its immediacy, so inchoate and unfocused as not to be recognizable by us as experience (i.e., by us as experience) until others have held us accountable and, as a result, we begin to hold ourselves responsible (MW 14: 18, 216-17) for the conjunctions between what we do and what we suffer (or simply undergo). This however should not be interpreted as an example of radical constructivism; rather it should be seen as an implication of pragmatic intelligence. The given is never simply given; put positively, it is always in some fashion taken (LW 1: Ch. 4; LW 12: 127). Even in the most uncontrolled phases of our primary experience selective attention is an ineliminable function (again, LW 1: 34). Selective attention is inevitably woven into a fabric involving potentially debilitating inattention (Hagberg 2008: 260-61).

The appeal to experience is analogous (if only remotely analogous) to what is involved when a competent speaker addresses a very young child who is barely more than an infant in the etymological sense. The infant becomes a speaker by being addressed by others as one (as someone whose babblings are already to some extent utterances). Analogously, experience becomes something to which we can reliably appeal by being that to which appeals are made. Experience as a court of appeal is constituted as such by the conscientious efforts of deliberative agents. In stressing this point, however, I do not intend to privilege unduly the juridical metaphor, especially since my intention is to move away from Kant, not to reinforce his authority. Other metaphors are indeed needed to highlight other facets of experience. I might appeal to a friend for reassurance or to a lover for affirmation of my singularity. The appeal to experience is, in any event, simultaneously an appeal to one's own experience and to the experience of others. On this occasion, however, I want to focus most of all on the deeply personal dimension of human experience, without thereby neglecting the inevitably communal dimension. That is, I want to focus primarily on what is entailed in an appeal to one's own experience, though I fully concede that your experience and mine are far from separable and, in numerous cases, hardly distinguishable.

No point is more important to stress than this one: The appeal to experience can be either naïve or critical (Smith 1967: 6-8). If naïve, it turns out, at some point, to be a betrayal of experience. For the experienced person is anything but naïve. Indeed, such a person is, virtually, by definition one who is resolutely disposed to be skeptical of naïve claims, especially when such claims are entwined with personal pretention or simply presumptuous attitudes. To repeat: if the appeal to experience is naïve, then anyone who makes such an appeal is destined to be exposed, at some juncture, as someone entangled in a betrayal of experience. The experienced person is, accordingly, a practical (not a rhetorical or theoretical) skeptic, that is, a skeptic in the etymological rather than the textbook sense. Above all else, then, the disposition not only to pose questions but also to be open to questioning all facets of our questions themselves defines the skeptic in this sense. Etymologically, the skeptic is the inquirer and, perforce, the questioner - one who is alive to the force, implications, and salience of questions ordinarily left unasked. To invoke an expression from Ludwig Wittgenstein ("Question the question"), however, it is not enough simply to question; we must question our own questions. We must interrogate the motives and ideals animating as well as the protocols and indeed spirit structuring our forms of interrogation. Skeptical reflexivity of course returns, time and again, to the interminable task of reflexive interrogation: put quite simply, the task of calling 
ourselves into question. Part of the goal of this essay is, however, to suggest that selfinterrogation and self-trust are of a piece (Emerson; Day). For the moment, it suffices to say that a critical stance toward one's own experience paradoxically involves questioning what one must, in some fashion, trust. The distrust implicit in the very act of questioning turns out to be an expression of trust (or faith) in our experience as a self-corrective and self-transcendent process. We cannot help but fall back on our own experience. For experience is not only that with which we have been entrusted ${ }^{12}$ it is also that in which we are forced to put our trust. It is, in the end (that is, in the meantime), what we willynilly go on, especially in our efforts to go on (see, e.g., Wittgenstein PI, \#179; Cavell 1990: 70). As it presently stands, however, it is not yet entirely trustworthy. Making our experience trustworthy can only begin, in earnest, by entrusting ourselves to our experience (again, Day). Trust is inevitably the first word, whereas trustworthiness is ideally the "last" one (though there is no more a final or ultimate word than there is, without ambiguity or uncertainty, an inaugural or initiating one).

11 If our experience is critical rather than naïve, then another set of dangers inevitably appears upon the stage of our thinking. These inevitable dangers are, for the most part, disguised characters, some of them being indeed seductive figures whose alluring power might have far more destructive sources than even these seducers realize. It is likely that they have misled themselves. In other words, the forms of seduction almost certainly involve, for the seducer no less than the seduced, a subjection to a series of illusions. For example, Immanuel Kant in his Herculean effort to save human experience from Humean "skepticism" has, in my judgment, betrayed experience at least as much as Hume. Those who are seduced by his critique of reason, a project inescapably encompassing a critique of experience, are, therefore, blocked from their own experience, in subtle, frequently imperceptible, but ultimately destructive ways. But so too is Kant himself. As tempting as it is to see either the pragmatic or the perfectionist appeal to human experience as a transformation of the transcendental approach, it is better to resist than to succumb to this temptation. Such, at least, is what I hope to show next.

\section{The Critique of Experience: Transcendental or Experiential?}

For my own purpose, however, the principal point is that the form in which a critique of our own experience is most humanely and wisely undertaken need not be the form in which Kant cast his critiques of reason and, consequently, articulated his critical stance toward cognitive, moral, and aesthetic experience. A critique of experience is unavoidable. Naiveté is, experientially, precluded. Experience is indeed the name for a process of overcoming the myriad forms of human naiveté, both historically pervasive ones and specifically contemporary Gestalten. It not only invites but also demands interrogation. Our experience proves itself trustworthy by being subjected to relentless critique, incessant interrogation, innumerable queries As Marx, Nietzsche, Freud, and indeed others have stressed, such critique is always an exercise of courage. As it stands at any actual moment of either our personal lives or collective histories, however, our experience is not entirely trustworthy, even in those instances (cf. Day 2000), or in those contexts, when it has undergone dramatic trans- formation as a result of our conscientious critiques. It more often than not needs to be rendered more trustworthy. Our opposition to the (allegedly) Humean dissolution of human experience into an 
arbitrary conjunction of sensory impressions need not drive us to a transcendental critique of human rationality, even though familiarity with the details of such a critique, especially as developed by such a philosophical genius as Kant, can be immensely suggestive for how other forms of critique (including ones breaking decisively with the tenacious tradition of transcendental philosophy) are to be carried out. So, the critique of experience is (to repeat) inescapable, whereas the form of that critique is debatable. On this occasion, I want more than anything else to suggest that this form might be something more deeply akin to the one we encounter in the writings of Stanley Cavell than the form we see exemplified in the texts of Kant. Of course, Cavell's critical engagement with experience owes much to Kant's transcendental critiques of rationality in its distinguishable forms (Neiman). But it is not simply or even primarily a variant of the form we encounter in Kant. For Cavell's writings in this regard mark a decisive break, a dramatic rupture, with the transcendental tradition, thereby opening a creative space for a truly novel engagement with human experience. The motives and implications of this engagement are as deeply in tune with our time as Kant's were in sync with his epoch or moment in history.

13 In any event, a critical stance to our precarious experience need not reenact the Kantian turn. Our experience is precarious because we are typically careless but (of even greater pertinence) we are, all too often, cowardly. To use a wonderful expression employed by William Ernest Hocking, we have to have the courage of our experience. ${ }^{13}$ In falling to have this courage, we in effect fail to have nothing less than the experience itself (Colapietro 2008). Put otherwise, the coin by which our experience is purchased is courage: our experience is not ours lest there is, especially at critical junctures [crisis], a courageous refusal to cede our personal experience to various authorities (Cavell 2005). To be thr own back on our experience is, in effect, to be thrown back on self-trust. But what makes this especially problematic and disconcerting is that, at just those times when we are thrown back on self-trust, we are ordinarily least confident about the trustworthiness of our experience. Practically, this means that we are least confident of our mastery of an aspect of a practice especially relevant to the execution of a task, in the here and now, frequently a task thrust upon us (not infrequently, an inescapable task). In a word, we are least confident about ourselves. Do we possess what the moment demands of us, what the situation asks so urgently of us? The felt "No" is no warrant for personal annihilation, for self-abnegation; rather it is a reason for self-affirmation. Trust in the self helps create the self. More fully, trust in the self helps create not only the self (hence, a self worthy of being trusted) but also a depth of experience itself worthy of our trust. of course, such a trustworthy self and such trustworthy experience are not in the least separable. In the end, they are identical.

The critique of experience might take the form of an experientially animated and guided process wherein unblinking attention to immanent factors, above all, immanent tendencies, on the one hand, and immanent failures, frustrations, fulfillments, and facilitations, on the other, is the decisive factor (Hagberg 2008). In Pragmatism, William James writes: "Nothing outside of the flux secures the issue of it. It can hope salvation only from its own intrinsic promises and potencies" (1978: 125).

15 The critique of experience is, at bottom, rooted in our experience of crisis, where the word crisis designates (as the etymology suggests) not necessarily a catastrophe but primarily a moment of decision (though the decision need not be a conscious or deliberate one). In his role as an inquirer, committed to the ceaseless advance of 
theoretical knowledge, Kant experienced a crisis: the Humean challenge needed to be met, for otherwise Kant in this role could not go on (at least, could not go on in good intellectual conscience). What we witness in Kant's first Kritik is accordingly a response to an existential crisis, not simply the solution of a philosophical puzzle. The experience of crisis might also be exemplified by being challenged by a child as to why one proceeds in a certain fashion, acts in a particular way. Wittgestein: "This is simply what I do." The question, time and again, turns out to be: How am I to go on (Wittgenstein, PI, \#179)?

\section{The Recovery of Self-Trust/The Rediscovery of the Ordinary}

Though I have already touched upon this theme, it is instructive to see the way in which Cavell links experience and self-trust. We have no option but to trust our experience. But, in doing so, we are eventually, perhaps quickly, led to the realization that experience is not up to the demands we are placing upon it. At this point, we might turn aside from experience and seek for resources from some other source. This move is predicated on the conviction that experience is inherently and invincibly deficient precisely in providing us with the means for (say) more responsibly conducting our inquiries, more justly arranging our institutions, or more sensitively shaping our responses to the singular beings with whom our own singular lives are so intricately entangled. But we might also turn back to experience in a self-consciously critical manner, animated by the goal of transforming our experience into something more trustworthy than it now is (Cavell 2005: 12). The present inadequacies of our experience are not, in themselves, a sufficient warrant for jettisoning our trust in ex- perience. To rely uncritically upon our present experience is naïve; however, to jettison completely that experience is selfstultifying, indeed, self-destructive. Maturity, inevitably the result of a series of disillusionments, need not eradicate all trust in either the self or the world as a source of warrants and as a site of fulfillments (the self-in-the world but also the world as the matrix from which selves spring and the habitat in which they dwell). Trust might - in truth, trust must - survive the process of maturation. This actually reverses the order or, more precisely, suggests too simple a picture of the place of trust in this process, for trust needs to be seen as integral to the origin of this process as much as observable as a result. Trust as that which survives the process is a transformation of what inaugurates and, at every turn, sustains the process. In fact, the process of maturation is arrested in the most tragic ways when the self is unable or unwilling to trust itself or the world in a sufficiently expansive and (in certain respects) reckless manner ${ }^{14}$ Again, the inability or unwillingness of individuals to trust themselves is ultimately identifiable with their incapacity or refusal to trust the world as a stage, especially for their unrehearsed exertions and interventions. Self-trust is almost certainly the better name for what Emerson celebrates in "Self-Reliance" and it is indeed one of the names he himself uses to identify the object of his praise. Self-trust does not preclude self-suspicion or self-doubt of every sort; indeed, it often invites and even demands that certain suspicions be take seriously, that certain doubts be pressed strenuously.

17 No philosopher has enabled us to appreciate the contemporary relevance of transcendentalist authors (especially Emerson and Thoreau) more than Stanley Cavell. In particular, his reading of Emerson is truly Emersonian. On this occasion, however, I want to turn most of all to Pursuits of Happiness: The Hollywood Comedy of Remarriage, a work no 
less inspired by Emerson than, say, Conditions Handsome and Unhandsome or This New Yet Unapproachable America. What Cavell in this book says about film is immediately applicable to music. So, when he asserts, "A reading of a film sets up a continuous appeal to the experience of the film, or rather an active memory of the experience (an active anticipation of acquiring the experience)" (1981: 11), we might immediately translate: Listening to a piece of music "sets up a continuous appeal to the experience of the film, etc." It demands us to check the work or performance out, again and again, but also to check out (to take careful note of) our critical responses and imperfect understanding, then, finally, to check (or suspend) our juridical impulses and even to tarry in our imperfect understanding. ${ }^{15}$ Even popular films such as The Lady Eve or The Philadelphia Story are to be read as carefully as philosophical texts; but, then, pieces of music are to be listened to as painstakingly as such films.

"Checking one's experience is," Cavell suggests, "a rubric an American, or a spiritual American, might give to the empiricism practiced by Emerson and by Thoreau" (Cavell 1981: 12). To be engaged with a film or a piece of music demands checking one's experience of that engagement. But there is an intended ambiguity here: on the one hand, we need to check our experience in the sense of consulting it; on the other, we need to check it in the sense a pilot tests the controls on a plane. Cavell is explicit in stressing this twofold sense plus yet a third meaning: "I mean the rubric [of checking one's experience ] to capture the sense at the same time of consulting one's experience and subjecting it to an examination, and beyond these, of momentarily stopping, turning yourself away from its expected, habitual track, to find itself, its own track: coming to attention" (Cavell 1981:12). He is also emphatic about the purpose of doing so: "The moral of this practice is to educate your experience sufficiently so that it is worthy of trust" (Cavell 1981: 12, emphasis added). Encouraged by Emerson and Thoreau, "one learns," Cavell adds, that without this trust in one's own experience, expressed as a willingness to find words for it [at least, as a drive to articulate it in some medium or other, though not necessarily in language], without thus taking an interest in it, one is without is without authority in one's own experience" (emphasis added; cf. Philosophy the Day After Tomorrow). Such self-trust is however only one half (or less) of the story. For it "is fundamental to this view of experience not to accept any given experience as final but to subject the experience and its object to the test of one another." Accordingly, the appeal to experience, so understood, cannot avoid being somewhat convoluted: it must turn upon itself, in order to be able more confidently in the future to turn to itself. This appeal does so, initially, for the sake of testing but, ultimately, for the sake of strengthening and solidifying experience, as a resource for improvisation.

The philosophical appeal to experience is ordinarily conceived in a narrowly epistemological context, whereas the critical or reflective appeal (cf. Diamond 2012; cf. Murdoch 1997: 33-42, i.e., "Thinking and Language") being advocated here is envisioned in reference to the entire range of human engagements (Smith 1981). Part of the task of the pragmatists no less than the perfectionists is to re-make the philosophical appeal into such a reflective appeal, the appeal of situated agents (or implicated actors) to their personal in- volvement in an ongoing endeavor. The concern is not to rise above, but to go on: the accent falls not on transcendence and distance but immanence and involvement (or participation). It involves, at once, appropriating more fully our own experience and imaginatively distancing ourselves from that experience in such a way as to open a range of possibilities not otherwise available to us. The paradox here is that in making our 
experience more truly our own we make ourselves other than we have been: in making my experience more fundamentally mine I make me into someone else, the most intimate of strangers, the most uncanny of intimates.

A truly critical appeal to experience must, I urge, take the form outlined by Cavell in the passages from Pursuits of Happiness quoted above. It exhibits the degree and form of selftrust requisite for self-interrogation. It fights against nostalgia. In Philosophy the Day After Tomorrow, Cavell astutely observes: "Nostalgia is an inability to open the past to the future, as if the strangers who will replace you will never find what you have found" (Cavell 2005: 218). In fighting against nostalgia, however, someone making such an appeal fights for the present. But it fights for the present precisely as the site wherein creativity emerges and often explodes upon the scene. ${ }^{16}$ We might take extemporaneity as the opposite of nostalgia as Cavell defines the latter word in Philosophy the Day After Tomorrow. Whereas nostalgia is the inability or perhaps the unwillingness to open the past to the future, extemporaneity can be understood as the willingness to trust both our present resources and future practitioners sufficiently to open the past to the future. Of course, the present alone can be the site in which the past is opened, by the creative exertions of extemporaneous actors implicated in unfolding dramas, to the future (cf. LW 14, Ch. 22). The open-ended lineage provides, among other things, paths back to earlier moments of inspiration. The innovations of Milton do not cut us off from Shakespeare, any more than those of Charlie Parker cut us off from the improvisations of Louis Armstrong. The drive forward very often makes available to us the past from which it pushes off. Indeed, by virtue of such innovations and improvisations, the past is rendered more vibrantly and vitally available to us than unimaginative replications would leave it. While nostalgia is unable - or unwilling - to expose the past to the risks of the future, self-trust is more than self-trust: it encompasses trust of our successors to make of the past something vital and vibrant, also of the past itself to be able to incorporate our modifications without destroying its integrity.

\section{The Preordained and the Extemporaneous}

21 A conversation is, Michael Oakeshott suggests, "an unrehearsed intellectual adventure" (Oakeshott 1991: 490). While being an intellectual adventure, a conversation can also be a personal, social, cultural, and political one as well. More than anything else, what makes such a multifaceted adventure possible - of greatest pertinence, what enables an unrehearsed sequence of distinct gestures to add up to a more or less coherent whole - are past performances. These are in effect rehearsals, while sometimes they are in intent just that: deliberate preparations for extemporaneous performances. Although there might be a paradox here, there is no contradiction. Let me try to explain why. If everything in one's past in effect serves as a rehearsal for what one is now extemporaneously doing, then that might seem to preclude extemporaneity. The opposite is, in truth, the case: no amount of rehearsal or preparation eradicates entirely the need for improvisation, no matter how unimaginatively meet or mechanically satisfied. The living organism is blessed - and cursed - with an immeasurable degree of irrepressible spontaneity, despite some regimes of discipline to transform the human animal into a perfectly predictable or, simply, a thoroughly reliable automaton. Extemporaneity cannot be eradicated: the life of the organism is realized in time and, moreover, the unpredictable sequence of interpenetrating events is both itself a site of novelty and an invitation to respond 
creatively to what is unfolding, here and now (in other words, to the cutting edge of some inherent tendencies in the temporal continuum of lived experience). history?
What gives any human action both its immediate point and its ineluctable claim upon an intelligibility far transcending any actual moment, especially an intelligibility far transcending the immediate present, is a vast, vague background of actions, agents, and the world in which the strivings, struggles, defeats, and successes alone make sense. Our performances, even our most routine ones, are to some degree improvisations.

What makes an unrehearsed performance possible is, paradoxically, the ordinarily vast repertoire of prior performances. But the performer has not done precisely this before. What the past performances enable is a truly present performance, more differentially responsive to the unique demands of the actual situation (cf. MW 14: Ch. 18). Such a performance is not a mere replication of previous exertions. It is inevitably, if not always obviously, let alone dramatically, an instance of repetition and difference (cf. Deleuze 1994), thus an instance wherein the repetition is inherently a moment of differentiation, whereas the difference is inevitably a phase in a process wherein echoes and traces of other phases are legible. Closely connected to this point, it is as inheritors that we are improvisers. The very process of inheritance is far from an unimaginative or indeed passive one. Think here of how a child acquires language. At the heart of this acquisition, there is the creative, playful, and (in many respects) spontaneous engagement with the competent speakers of a linguistic community. Linguistic inheritance is both a personal and communal achievement; moreover, it is the result of (again) both an imitative and a creative activity on the part of the inheritor.

For the most part, breaking "free" of a tradition has point and power, justification and value, only as an act wherein someone appropriates more deeply some resource of the very tradition from which the individual is struggling to free herself. It is rarely the case that we can break free in any decisive, let alone any thoroughgoing, way from a tradition in which we have been reared (see Scott 1996 on lineage). The contemporary contrast between "traditional" and "modern" societies is to a great degree an instance of selfmystification. Premodern societies are claimed by many social theorists to be traditional, whereas modern ones are said by these theorists to be post-traditional (Giddens 1990: 4). Is any human society so bound by tradition as to preclude the very possibility of extemporaneity? So, too, is any culture so structured by its rejection of tradition as to escape the claims and influence of an intricate meshwork of intersecting traditions? ${ }^{17}$ Is not anti-traditionalism itself a tradition characteristic of a certain epoch in Western

Conversin' with the Elders is the title of a CD by James Carter (cf. Colapietro 2009). It reminds us of a leitmotiv in this paper: the metaphor of conversation. The most innovative jazz musicians know the "music" and this practically means that they know a variety of traditions of musicking (Small 1998a). The conversation in question is ineluctably intergenerational. It is, in its innermost character, an ongoing tradition: as such, it is a transformative process in which representative figures from distinct traditions, most urgently immediate elders and their more or less acknowledged offspring $^{18}$ oppose one another, learn from one another, cast aspersions, utter denouncements, offer encouragement, maintain affection, and do much else.

The scenes of our everyday lives are ones of vital improvisation. ${ }^{19}$ In this quotidian sphere, we are doing nothing less than making up our lives as we go along. ${ }^{20}$ There are, to 
be sure, inherited scripts or (more appropriate for this context) inherited charts or scores. The relationship between score and performance, analogous to that between dictionary and usage, deserves comment here.

Those brought up in literate cultures in which formal documents are invested with sacred authority or, at least, something akin to such authority, also ones in which symbolic practices such as storytelling, musicking, and of course governing require (at least for culturally recognized or authoritative practitioners) specific forms of literary competence, are likely to misunderstand what is most vital. The constitution of a country is, for example, a distillation of the commitments of a people. Its locus is first and foremost in the habits of its citizens, including the disposition to check their actions against the document itself (i.e., against the explicit protocols of those earlier citizens in whom present citizens continue to invest a constitutive authority). Or take the example of a dictionary. Indeed, just what is a dictionary? Though odd sounding, the question is far from unintelligible; though not obviously germane to our inquiry, it is in fact of the greatest salience. The normative function of a carefully compiled lexicon cannot be denied. But just what is a dictionary and how does it acquire its widely acknowledged authority regarding the (at least) apparent vagaries of contemporary usage? A dictionary is, at bottom, a compilation of reminders of how a particular linguistic community actually uses words. But why does actual usage dictate or determine proper usage? More pointedly, why is it not appropriate to insist that the way words have been actually used by the community in which I am a participant cannot by itself determine the way they ought to be used here and now? How can mere facts about established usage determine semantic norms regarding the permissible or, more strongly, requisite deployment of a determinate set of linguistic signs?

These questions cannot be adequately addressed here. They can be barely addressed at all. Suffice it to say, on this occasion, that we ultimately have to fall back on the confession, "This is simply what we do - or what we say" (cf. Wittgenstein). We can of course give reasons or, just as likely, elaborate narratives that go some distance toward making what we do or say intelligible. Beyond this, we can go some distance toward justifying these practices, but the justification cannot avoid being circular. There are circles and there are circles. If the circle takes the form of a spiral, and in turn if the spiral is invincibly, ineluctably, open-ended, the circularity of our justification need not be vicious.

What is true of constitutions and dictionaries is, mutatis mutandis, true of scripts and scores. In a culture such as ours, one disposed to invest the highest authority in formalized procedures, codes, and protocols, it is commonplace to see a musical performance as secondary to a formal score. The authority and originality of the composer of such a score are, to a remarkable degree, allowed to constrain, if not to eclipse entirely, the creativity and resourcefulness of the performers (Small). It is as though the dictionary dictated in the most minutely detailed manner the vocalizations of speakers in situ. There is much to be said for the dominant forms of Western musicking, with their overriding emphasis on musical literacy and the exacting "interpretation" of magisterial compositions. But the rigidly hierarchical world of such musicking, also the commitment to an antecedently scripted performance, stand in stark opposition to fluidly democratic relationships and vibrantly extemporaneous performances. The rigidly hierarchical and antecedently fixed cannot, from the perspective of either pragmatism or perfectionism, be allowed to preclude the flexibly democratic and historically emergent. 
The extemporaneous creativity of unrehearsed conversation, in its most quotidian forms no less than in its more disciplined ones, ${ }^{21}$ needs to be accorded wider recognition and greater authority than they have at present. This brings us, at last, to our ultimate aim: jazz improvisation as an arresting example of just such extemporaneous creativity.

\section{Time as Experience/Experience as Temporality: Reprise} human experience. "The fundamental fact about our experience is," James stresses, "that
it is a process of change" (MT: 220). With a slight but significant variation, he notes: "experience as a whole is a process in time, whereby innumerable terms lapse and are superseded by others that follow upon them by transitions [...] which are themselves experiences, and must in general be accounted at least as real as the terms which they relate" (MT: 231). Whatever is immediate in any experience is, James adds, always provisionally so and indeed situationally so. "But owing to the fact that all experience is a process, no point of view can ever be the last one. Every one is insufficient and off its balance, and responsible to later points of view than itself" (MT: 221; emphasis added). "Experience leads ever on and on, and objects and our ideas of objects may lead to the same goal" (MT: 258). "Experience is a process that continually gives us new material to digest" (MT: 208). ongoing flux of our finite lives implies just what James emphasizes in a text just quoted: "no point of view can ever be the last one. Every one is insufficient and off its balance, and responsible to later points of view than itself." But what he claims regarding science (more precisely, a certain understanding of scientific accomplishment) might have much wider applicability. In The Varieties of Religious Experience, he suggests:

[T] he divorce between scientific facts and religious facts may not necessarily be as eternal as it at first sight seems, nor the personalism and romanticism of the world [...] be matters so irrevocably outgrown. The final human opinion may, in short, in some manner now impossible to foresee, revert to the personal style, just as any path of progress may follow a spiral rather than a straight line. If this were so, the rigorously impersonal view of science might appear one day as having been $a$ temporarily useful expedient rather than the definitively triumphant position which the sectarian scientist at present so confidently announces it to be. (James 1985: 395, note 8 , emphasis added)

In a universe such as ours, especially for a species such as us, definitively triumphant positions are unobtainable. The best we can ever aspire to reach are temporarily useful expedients. Their utility may of course span decades or even centuries; but it does so principally by their remarkable adaptability to novel circumstances In other words, there are definitive accomplishments, exemplary performances, but they fall short of being 
absolutely definitive or unsurpassably exemplary. The accomplishments of, say, Copernicus, Newton, Darwin, and Einstein unquestionably define for us what the practice of science must mean, just as the performances of (say) Armstrong, Ellington, Parker, and Coltrane exemplify what musical improvisation can be.

Rigorous formalism is more often than not an invaluable discipline, at least when subjection to the rigors of this discipline is voluntarily embraced rather than externally imposed. But formal anarchism, at least in a weak sense, ${ }^{22}$ can be no less valuable a personal discipline, ${ }^{23}$ at least when the demands of sustaining such a stance (rather than simply the initial impulse to break free from established forms) are imaginatively and, thus, courageously met. The initial impulse exposes itself as infantile or, at best, adolescent, if it does not struggle to find ways of going on. ${ }^{24}$ The spirit of such anarchism, at least with respect to philosophy, is exuberantly expressed by James in a letter to Bergson (December 14, 1902) when he proclaims: "How good it is sometimes simply to break away from all the old categories, deny old worn-out beliefs, and restate things $a b$ initio, making the lines of division fall into entirely new places!" (Perry: 606). Of course, it is impossible completely to break away from "all the old categories," to deny all our inherited beliefs. The process of twisting free, however partial and provisional, from the constitutive forms of some consolidated practice may be truly emancipatory, because transformatively enlivening. As Paul Klee notes in one of his notebooks, "form is the end, death. Form-giving is movement, action. Form-giving is life."

From a pragmatist perspective (at least, from a Deweyan one), virtually all art is improvisational. In many cases, perhaps most, however, what we encounter is the product of improvisation, not the process itself (cf. Sawyer 2000: 149-50). But the product bears the traces of its origin in such a process. At least, this is Dewey's position: "A rigid predetermination of an end product whether by artist or beholder leads to the turning out of a mechanical or academic product" (LW 10: 143; cf. Sawyer 2000: 154). Artists of course care about what shape or form their works take; but they tend to care about "the end-result as a completion of what goes before and not because of its conformity or lack of conformity with a ready-made antecedent scheme" (LW 10: 143). The self-trust of the artist is as much as anything a trust in the process: its characteristic form is a far from begrudging willingness "to leave the outcome to the adequacy of the means from which it issues and which it sums up." In the case of some artists, however, such self-trust points toward the felt inadequacy of means toward which the work points and which it as yet has failed to attain. The work as a work is an invitation to take up and renew the efforts of the artist to carry forward the process, but this task requires developing means beyond anything presently possessed. Artists trust themselves and their audiences enough to devote themselves to the cultivation of unprecedented skills and sensitivities, that is, to hope that sustained, imaginative effort will equip them with what neither they nor their audience now possess. In any event, the "consummatory phase of experience - which is intervening as well as final - always presents something new. Admiration always includes an element of wonder." (LW 10: 143-44). For Dewey, then, art is always the result of improvisation, even when the process by which the work came into being is, at least in part, hidden from those who encounter the work afterwards. Given the importance of this point, quoting Dewey at further length seems warranted:

The unexpected turn, something which the artists himself does not definitely foresee, is a condition of the felicitous quality of a work of art; it saves it from being mechanical. It gives the spontaneity of the unpremeditated to what would otherwise be a fruit of calculation. The painter and poet like the scientific inquirer 
know the delights of discovery. Those who carry on their work as a demonstration of a preconceived thesis may have the joys of egotistic success but not that of fulfillment of an experience for its own sake. In the latter they learn by their work, as they proceed, to see [or perceive] and feel what had not been part of their original plan and purpose..$^{25}$ (LW 10: 144)

Those works having the power to arrest and sustain our attention trace their origin, in part, to the unexpected turn, the unpremeditated effect, the creative process itself as an unrehearsed conversation with a sensuous medium, various traditions, inchoate impulses, dispositional tendencies, and much else. The work flows from such a conversation and embodies in itself the traces of this give-and-take, even when its form is, as in the case of a painting or a piece of sculpture, static (or synchronic) in some sense.

But music is inherently diachronic and, thus, perceptibly dynamic or fluid, while some forms of musicking are unquestionably extemporaneous. In the case of these forms, we might highlight a handful of features especially relevant to the topic of this paper. Musical improvisations such as those exemplified by Louis Armstrong's West End Blues, Paul Gonsalves's solo on Diminuendo in Blue, Charlie Parker's Koko, John Coltrane's Naima, or Sonny Rollins's Green Dolphin Street are themselves works of art crafted, intentionally yet spontaneously, as processes of improvisation. We are confronted with an invitational process, not a finished product merely suggestive of its improvisational origin. In the case of such improvisations, we are invited into the process in a more immediate and dramatic manner than we are when the product is presented apart from the process of its origination. Such a process precisely qua improvisation is: transactional, emergentist, collaborative, unpredictable, problematizing, ${ }^{26}$ and hence expressive beyond anything intended by, or known to, the improvisers at the time of their collaboration. ${ }^{27}$ What might seem contradictory to some, jazz ensembles rehearse to prepare themselves for the exacting demands of "an unrehearsed adventure" in real time before a live audience. Though some claim that such a performance precludes the possibility of editing or revising, it might be more accurate to say that what we are witnessing is a process of revising, though one that involves no less than re-envisioning what one is doing, what counts as a problem or difficulty.

What emerges from such a process is exactly what G. H. Mead highlights when he defines emergence. Much of his reflection on time is organized around the insight (at least, the claim) that "a reality that transcends the present must exhibit itself in the present" (Mead 1932: 11; cf. Mead 1938: 640-43). "The emergent when it appears is always found to follow from the past, but before it appears it does not, by definition, follow from the past" (Mead 1932: 2, emphasis added). To insist that the emergent must be, in principle, deducible from the past is to break with the pragmatists, for whom the universe is shot through with contingency and novelty. The novel and the contingent are not necessarily illusions due to our ignorance of the laws governing phenomena; they are, in some instances at least, nothing less than features of reality itself. The demands of intelligibility dispose us to stress continuity with the past and thereby compromise the extent to which the irreducibly novel explodes upon the scene, in the present. In contrast, the celebration of novelty inclines us to highlight rupture with precedent or antecedent. The pragmatist orientation invites us to take seriously the possibility of there emerging, here and now, novel forms of intelligibility (cf. Hausman 1984), but to treat no less earnestly the threads of continuity between the unfinished present and an apparently irrevocable past (see, however, Mead 1932: 2). For Mead, at least, "there is and always will be a necessary relation of the past and the present but [...] the present in 
which the emergent appears accepts that which is novel as an essential part of the universe, and from that standpoint rewrites the universe" (Mead 1932: 11). It is, in Mead's judgment, nothing less than the task of philosophy "to bring into congruence with each other this universality of determination which is the text of modern science, and the emergence of the novel" (Mead 1932: 14; cf. Sawyer 2000: 152). The emergence of novelty might be identified as the "text" of modern life, nowhere more legible than in the arts expressive of the ethos of modernity and its discontents.

The forms we have inescapably acquired in the course of our lives are either accorded the status of forms in the sense denigrated by Klee or they are deployed as resources for form-giving beyond anything dictated by these forms themselves. That is, they are either dead and deadening things or living and enlivening ones. The given forms are frequently accorded the status of absolutely authoritative texts, scripts, or scores; or, alternatively, the given forms are treated primarily as immediate resources for form-giving. Regarding the latter, the function of intelligence in its most vital form is the introduction and nurturance of novelty (Whitehead 1929 [1971]: 25; also 27, 32). Such intelligence is observable in virtually all domains of experience, but nowhere more manifestly than in the forms of musicking commonly called jazz improvisation.

It might be an exaggeration to assert, "the history of pragmatism survives most unexpectedly, and therefore most startlingly, in black music and contemporary experimental writing" (Magee 2004: 179). It is, however, no exaggeration at all to claim that the spirit animating especially James's pragmatism and indeed Cavell's perfectionism is truly akin to that animating these forms of musicking and writing. The philosophical celebration of creative intelligence obtains pertinence and power when conjoined to historical instantiations of extemporaneous creativity.

For much of our history, the achievements of art no less than those of philosophy have seemed to enable the transcendence of time, as such. More recently, however, an ethos of immanence has in certain circles, including those of pragmatists and perfectionists, discredited the ideal of such transcendence. But we are not imprisoned in time or history any more than we are in our own bodies. Whatever forms of transcendence are available to us, they are available in and through our temporality and historicity no less than our embodiment and sociality. In a poem ("in the time of daffodils," e. e. cummings insists, parenthetically, "(time from time shall set us free)." Pragmatists and perfectionists remove the parentheses: this is hardly an aside or a line to be separated, however slightly, from what most demands utterance. Only time from time shall set us free and such freedom is itself only a critical distance - better, a creative distance - from some facets of our inheritances and traditions, not from inheritance or tradition as such. Even so, the instances of twisting free from time in time is at once a human commonplace (witness the irrepressible spontaneity of ever yday conversations) and a remarkable achievement (witness the exemplary improvisations of such jazz musicians as Charlie Parker, Miles Davis, Bill Evans, John Coltrane, or Sonny Rollins). The given forms give way to formgiving, when just the right tone in an everyday exchange is struck or when jazz truly becomes (in the words of Sonny Rollins), "the music of surprise," for the performers (at least) as much as the auditory collaborators (i.e., what is ordinarily called the audience or listeners). 


\section{Conclusion}

43 comportment. The spontaneous creativity exhibited in our everyday extemporaneity cannot be gainsaid. Human perception is an endless source of irreducible novelty, but our conceptualization of our own perceptions tend, as James so brilliantly made clear, to efface the novelty no less than the fluidity of our experience. Reason as a juridical capacity is not to be utterly denigrated; it however needs to be supplemented. Intelligence as an irrepressible drive toward extemporaneous novelty needs to be seen for what it is - the human face of human rationality (again, cf. Whitehead 1929 [1971]; also MW 14: 48-49, 134-38; LW 1, Ch. 10). The ongoing critique of reason is simultaneously an ever deeper interrogation of experience. When this interrogation is undertaken for rendering our experience more luminous, intense, differential, sustaining, and indeed startling (LW 1: 18; 305; also LW 10: 41), the appeal to experience is made, in a single stroke, more critical and more humane.

Self-trust in its most admirable form underwrites self-interrogation of a relentless and (in certain respects) frequently ruthless character. Self-interrogation in such an adverse form alone makes our trust in our own experience trustworthy, for it helps to transform experience into something more secure yet plastic, more stable yet protean, than it otherwise would be. These are, at least, the directions in which we are invited to move the ways we might go on - in light of our experience of extemporaneity (at least, as I interpret this experience).

These modes of temporality constitutive of this experience - e.g., the unblinking confrontation with the irrevocability of any actual past linked to the imaginative resignification of the import of this irrevocable actuality; the present as a scene of struggle between a stubborn past and an irrepressible future; the future as, at once, elusive and fateful - (the modes of temporality) are, especially as affective processes of personal entanglement, nowhere more sensuously available to us than in musicking, above all, jazz improvisation. Put far more simply, time as experience and experience as temporality are articulated more arrestingly, intricately, and emphatically in musicking than anywhere else. In music, art as experience takes the form of time as experience. In this form, our experience of time and the temporality of experience are not so much made into objects of contemplation (though to some extent this is true) as we are made into processes of transitions, transience, and transfiguration. That is, the human animal is afforded a unique opportunity to have the time of its life, in the multifarious configurations in which experienced time unfolds, above all, in the interstices of everyday life. Experience is first and foremost had, not known (LW 1: 28). ${ }^{28}$ But there is having and there is having! Experience had as art - time had as music - are more philosophically illuminating and, of greater importance, more humanly centering than philosophers and indeed other theorists have yet discerned (cf. Bowie 2009).

My reflections on time as experience are designed, more than anything else, to exemplify a way we as philosophers might go on - and go on in an innovative way. In our most creative moments, our unwitting quotations of others are audible (cf., once again, Emerson's "Quotation and Originality"). But, in our most seemingly routine performances, a nuanced extemporaneity (however slight and thus imperceptible) is discoverable. Time as experience is, accordingly, best approached in reference to 
experience as extemporaneity: the cutting edge of our ongoing experience is, in effect, a musical gesture. The significance of this gesture is affectively had only as a moment unto itself and a phase of transition from what precedes to what follows this moment. The intelligibility of this gesture forever eludes those who lack a feel for what is to be had in such sequences, ones often punctuated by a single note held for a sustained duration, but more often by a rapid sequence of different notes organized along distinct axes. The medium of articulation can only be that of music itself (Bowie 2009), though verbal and other forms of commentary might send us back to a piece or performance with new ears, with a more probing and appreciative feel for what resounds in this medium.

"We humans," James insists, are incurably rooted in the temporal point of view. The eternal's ways are utterly unlike our ways" (James 1977 [1909]: 23). But much of the history of philosophy has been animated by an impulse to transcend temporality and, thereby, to make our ways the eternal's ways. What the pragmatists in their way and Cavell in his make clear is what another inhabitant of Cambridge, MA, noted when he wrote, "time from time shall set us free" (cummings). The transcendence of time is a transition and indeed an achievement in time. The experience of eternity is, paradoxically, an arresting moment in the ongoing rush of the temporal flux itself. Very few people who have ever listened to music have not felt themselves to be lifted out of time and suspended in eternity, however briefly (!). Our experience of music discloses the feel of time, including the felt sense of a present possibly inclusive of the entirety of past, present, and future (Neville), better than any other medium of articulation, not least of all because this experience is itself essentially temporal. Time is of the essence - of music. In its affectively charged disclosure ${ }^{29}$ of the most intricate textures of experiential temporality, we are provided with an impetus to acknowledge ${ }^{30}$ that we are indeed "incurably rooted in the temporal point of view."

Temporality and the perspective it demands of us are, however, not diseases. They are decidedly not anything from which we need to be cured. Much rather, philosophical therapy is needed for counteracting our insistence upon casting ourselves as time's stepchildren ${ }^{31}$ (Lovibond 1983: 206). Despite our fantasies, philosophical and otherwise, we were not abandoned by eternity on time's doorstep one cold evening: we were formed and nurtured in time's womb and exiled into other spheres of temporality. Music more than anything else and jazz more than any other form of music help us to avoid this impiety inherent in the fantasy that we are eternity's child (cf. Santayana on impiety). As agents, we are in no small measure the playthings of time. But, precisely as such playthings, we can mount our resistance and improvise the script or (better) the score as we have inherited it, if only just a moment ago. Extemporaneity is shot through with resistance and reparation, rejection and reconciliation, implosion and renovation, quotation and originality, repetition and - difference. The sensuous shapes of musical extemporaneity are, in sum, invaluable for discerning this and much more. 


\section{BIBLIOGRAPHY}

ANDERSON D. R., (1987), Creativity and the Philosophy of C. S. Peirce, Dordrecht, Martinus Nijhoff. BARAKA A. [LERoI Jones], (1999), Blues People: Negro Music in White America, New York, Harper Perennial.

BERLINER P., (1997), "Give and Take: The Collective Conversation of Jazz Performance," in Sawyer (ed.), 9-41.

BOWIE A., (2009), Music, Philosophy, and Modernity, Cambridge University Press.

BRIOSCHI M. R., (2013), "How Novelty Arises in the Fields of Experience: A Comparison between W. James and A. N. Whitehead," article in this issue of the European Journal.

CARTER J., Conversin' with the Elders [Compact Disk].

CAVELl S., (1981), Pursuits of Happiness: The Hollywood Comedy of Remarriage, Cambridge, MA, Harvard University Press.

CAVELl S., (1998), "What's the Use of Calling Emerson a Pragmatist?," in Dickstein M. (ed.), The Revival of Pragmatism, Durham, NC, Duke University Press, 72-80.

CAVELl S., (1990), Conditions Handsome and Unhandsome: The Constitution of Emersonian Perfectionism, Chicago: University of Chicago Press.

CAVELL S., (2004), Cities of Words: Pedagogical Letters on a Register of the Moral Life, Cambridge, MA, The Belknap Press of Harvard University Press.

CAVELl S., (2005), Philosophy the Day After Tomorrow, Cambridge, MA: The Belknap Press of Harvard University Press.

COLAPIETRO V., (2003), “Loci of Creativity: Fissured Selves, Interwoven Practices," Manuscrítica: Revista de Crítica Genética, 11, 59-82.

COLAPIETRo V., (2008), “Experience Ceded and Negated," Journal of Speculative Philosophy, 22, 2, 118-26.

COLAPIETRo V., (2009), "Psychoanalysis and Jazz: Familiar Bedfellows in a Strange Setting," Semiotics 2008, edited by John Dewey and Leonard G. Sbrocchi, Legas Publishing Company.

CUMmING N., (2001), The Sonic Self: Musical Subjectivity and Signification, Bloomington, IN, Indiana University Press.

DAY W., (2000), “Knowing as Instancing: Jazz Improvisation and Moral Perfectionism," The Journal of Aesthetics and Art Criticism, 58, 2, 99-111.

DELEUZE G., (1994 [1968]), Difference and Repetition, New York, Columbia University Press.

DEWEY J., (1889-1892), The Early Works of John Dewey, vol. 3 (EW 3), ed. by J. A. Boydston, Carbondale and Edwardswille, Southern Illinois University Press 1969.

DEWEY J., (1903-1906), Essays on the New Empiricism, in The Middle Works of John Dewey, vol. 3. (MW 3), ed. by J. A. Boydston, Carbondale and Edwardswille, Southern Illinois University Press 1977. 
DEWEY J., (1911), "Epistemological Realism: The Alleged Ubiquity of the Knowledge Relation," in The Middle Works of John Dewey, vol. 6 (MW 6), 111-22, 1978.

DEWEY J., (1922), Human Nature and Conduct, in The Middle Works of John Dewey, vol. 14 (MW 14), ed. by J. A. Boydston, Carbondale and Edwardswille, Southern Illinois University Press, 1983.

DEWEY J., (1925), Experience and Nature, in The Later Works of John Dewey, vol. 1 (LW 1), Carbondale and Edwardswille, Southern Illinois University Press 1983.

DEWEY J., (1925-1927), The Later Works of John Dewey, vol. 2 (LW 2), Carbondale and Edwardswille, Southern Illinois University Press 1984.

DEWEY J., (1929-1930), The Later Works of John Dewey, vol. 5 (LW 5), Carbondale and Edwardswille, Southern Illinois University Press 1984.

DEWEY J., (1933-1934), The Later Works of John Dewey, vol. 9 (LW 9), Carbondale and Edwardswille, Southern Illinois University Press 1986.

DEWEY J., (1934), Art as Experience, in The Later Works of John Dewey, vol. 10 (LW 10), Carbondale and Edwardswille, Southern Illinois University Press 1987.

DEWEY J., (1935-1937), The Later Works of John Dewey, vol. 11 (LW 11), Carbondale and Edwardswille, Southern Illinois University Press 1987.

DEWEY J., (1938), Experience and Education, in The Later Works of John Dewey, vol. 13 (LW 13), Carbondale and Edwardswille, Southern Illinois University Press, 1-62, 1991.

DIAMOND C., (2010), "Murdoch off the Map: or Taking Empiricism Back from the Empiricists," Talk at the New School (December 2, 2010).

ELLISON R., (2001), Living with Music: Ralph Ellison's Jazz Writings, New York, Modern Library.

EMERSON R. W., (1971), The Collected Works of Ralph Waldo Emerson, edited by Robert E. Spiller, Alfred R. Ferguson, et al., Cambridge, MA, The Belknap Press of Harvard University Press. EMERSON R. W., (1982), Ralph Waldo Emerson: Selected Essays, edited by Larzer Ziff, New York, Penguin.

FALOMI M., (2010), "Perfectionism and Moral Reasoning," European Journal of Pragmatism and American Philosophy, 2, 2, 85-100.

GIDDENS A., (1990), The Consequences of Modernity, Stanford, Stanford University Press.

HAACK S., (2009), Evidence and Inquiry: A Pragmatist Reconstruction of Epistemology, New York, Prometheus Book.

HAGBERG G., (2008), "Jazz Improvisation and Ethical Interaction: A Sketch of the Connections," in Hagberg G. (ed.), Art and Ethical Criticism, Oxford, Wiley-Blackwell.

HAMPL P., (2000), I Could Tell You Stories: Sojourns in the Land of Memory, New York, W. W. Norton \& Co.

HAUSMAN C. R., (1984), A Discourse on Novelty and Creation, Albany, SUNY Press.

HELM B. P., (1985), Time and Reality in American Philosophy, Amherst, University of Massachusetts Press.

HENDERSON D., (1997), "What the Drums Had to Say - And What We Wrote About Them," in Sawyer (ed.), 67-93.

HOCKING W. E., (1930), “Action and Certainty,” Journal of Philosophy, 27 (24 April 1930), 225-38. 
ISEMINGER G., (2010), "Sonicism and Jazz Improvisation," Journal of Aesthetics and Art Criticism, 297-99.

JAMES W., (1977), A Pluralistic Universe, Cambridge, MA, Harvard University Press.

JAMES W., (1978), Pragmatism. Cambridge, MA, Harvard University Press.

JAMES W., (1978), The Meaning of Truth. (MT), Cambridge, MA, Harvard University Press.

JAMES W., (1985), The Varieties of Religious Experience, Cambridge, MA, Harvard University Press.

JOAS H., (1996), The Creativity of Action, Chicago, University of Chicago Press.

KANT I., (1968), The Critique of Judgment, New York, Hafner Publishing Co.

LANGER S. K., (1955), Feeling and Form: A Theory of Art, New York, Charles Scribner's Sons.

LANGER S. K., (1957), Philosophy in a New Key, Cambridge, MA, Harvard University Press.

LOVIBOND S., (1983), Realism and Imagination in Ethics, Minneapolis, University of Minnesota Press.

LYSACKER J., (2008), Emerson and Self-Culture, Bloomington, Indiana University Press.

MACINTYRE A., (2007), After Virtue, Notre Dame, University of Notre Dame Press.

MAGEE M., (2004), Emancipating Pragmatism: Emerson, Jazz, and Experimental Writing, Tuscaloosa, University of Alabama Press.

MARX K., (1978), The Marx-Engels Reader, edited by Robert C. Tucker, New York, W. W. Norton \& Co.

MEAD G. H., (1932), The Philosophy of the Present, La Salle, Open Court Publishing Co.

MEAD G. H., (1938), The Philosophy of the Act, Chicago, University of Chicago Press.

MONSON I., (1997), "What's Sound Got to Do With It? Jazz, Poststructuralism, and the Construction of Cultural Meaning," in Sawyer (ed.), 95-112.

MURDOCH I., (1997), Existentialists and Mystics: Writings on Philosophy and Literature, New York, Allen Lane, The Penguin Press.

NEIMAN S., (1997), The Unity of Reason: Rereading Kant, Oxford University Press.

NEVILLE R. C., (1993), Eternity and Time's Flow, Albany, SUNY Press.

OAKESHOTt M., (1991), "The Voice of Poetry in the Conversation of Mankind," Rationalism in Politics and Other Essays, Indianapolis, Liberty Fund.

PARKER K., (2012), “Normative Judgment in Jazz: A Semiotic Framework," in De Wall C., \& Skowronski K. P. (eds.), The Normative Thought of Charles S. Peirce, New York, Fordham University Press.

PEIRCE C. S., (1931-1958), The Collected Papers of Charles Sanders Peirce, Cambridge, MA, The Belknap Press of Harvard University Press.

PEIRCE C. S., (1998), The Essential Peirce: Selected Philosophical Writings, volume 2 (1893-1913), edited by the Peirce Edition Project, Bloomington, Indiana University Press.

PERRY R. B., (1935), The Thought and Character of William James, Boston, Little, Brown and Company. Rosenthal S. B., (2000), Time, Continuity, and Indeterminacy, Albany, New York, SUNY Press.

SAWYER R. K., (2003), Group Creativity: Music, Theatre, Collaboration, Mahwah, Lawrence Erlbaum Associates Publishers. 
SAWYER R. K., (1997), “Improvisational Theatre: An Ethnotheory of Conversational Practice," in Sawyer (ed.), 171-93.

SAWYER R. K. (ed.), (1997), Creativity in Performance, Greenwich, Ablex Publishing Corporation. SCHATZKi T. R., (2010), The Time Space of Human Activity: On Performance, Society, and History as Indeterminate Teleological Events, Lanham, Lexington Books.

scoтT C. E., (1996), On the Advantages and Disavantages of Ethics and Politics, Bloomington: Indiana University Press.

SHORT T. L., (2008), “Peirce on Science and Philosophy," Philosophical Topics, 36, 1, 259-77.

SILVERSTEIN M., (1997), “The Improvisational Performance in Realtime Discursive Practice," in Sawyer (ed.), 265-312.

SMALL C., (1998a), Musicking: The Meanings of Performing and Listening, Hanover, Wesleyan University Press.

SMALl C., (1998b), Music of the Common Tongue: Survival and Celebration in African American Music, Hanover, Wesleyan University Press.

SMITH J. E., (1967), Religion and Empiricism, Milwakee: Marquette University Press.

SMITH J. E., (1981), “Philosophical Interpretation and the Religious Dimension of Experience,"

Logos, 2, 5-20.

SMITH J. E., (1983), The Spirit of American Philosophy, Albany, SUNY Press.

THOREAU H. D., (2001), Wild Fruits: Thoreau's Rediscovered Last Manuscript, New York, W. W. Norton \& Co.

WhiteHEAd A. N., (1966), The Function of Reason, Boston, Beacon Press.

WitTGENSTEIN L., (1973), The Philosophical Investigations, New York, Macmillan.

WitTGENSTEIN L., (1967), Zettel, Berkeley, University of California Press.

woolf V., (1932), The Second Common Reader, New York, Harvest.

\section{NOTES}

1. In Conditions Handsome and Unhandsome, Stanley Cavell writes: "Perfectionism, as I think of it, is not a competing theory of the moral life, but something like a dimension or tradition of the moral life that spans the course of Western thought and concerns what used to be called the state of one's soul, a dimension that places enormous burdens on personal relationships and on the possibility or necessity of the transforming of oneself and of one's society ..." (Cavell 1990: 2). See Falomi 2010. In identifying this as my ultimate goal, I am not suggest- ing or implying that this or this alone - is my main goal. I have several principal objectives, this being only one of them. Indeed, this essay is as much, if not more, a reflection on the most appropriate form of experiential appeal as it is a treatment of improvisation.

2. I do not mean to blur the differences between pragmatism and perfectionism, much less to suggest an exact equivalence or an easy harmony between Peirce, James, Dewey, and Mead, on the one side, and Stanley Cavell, Garry Hagberg, Richard Eldridge, and others, on the other side. In other words, I take with the utmost seriousness what Cavell argues in "What's the Use of Calling Emerson a Pragmatist?" and what he asserts, for example in Conditions Handsome and Unhandsome (see especially Cavell 1990: 13). 
3. "Tradition and custom, especially when emotionally charged, are a part of the habits that have become one with our very being" (LW 9: 11).

4. In "The Development of American Pragmatism" (1925), Dewey insists: "reason, or thought, in its most general sense, has a real, though limited function, a creative, constructive function" (LW 2: 13; emphasis added).

5. I am borrowing this term from Christopher Small. In Musicking: The Meanings of Performing and Listening, he informs us that: The word "is the present participle, or gerund, of the verb to music." For the verb, he proposes this definition: "To music is to take part in, in any capacity, in a musical performance, whether by performing, by listening, by rehearsing or praticising, by providing material for performance (what is called composing), or by dancing" (Small 1998a: 9; italics omitted).

6. In "Poetry and Philosophy" (1890), a commencement address given at Smith College, Dewey asserts: "after all, science means only knowledge - philosophy, only love of wisdom, only the essay at reaching the meaning of this experience of ours" (EW 3: 112). Cf. his "Philosophy and Civilization." Philosophy is, first and foremost, at attempt to understand more fully and deeply the meaning of our own experience.

7. In "How Should One Read a Book?" Virginia Woolf insists: “To admit authorities, however furred and gowned, into our libraries and let them tell us how to read, what to read, what value to place upon what we read, is to destroy the spirit of freedom which is the breath of those sanctuaries. Everywhere else we may be bound by laws and conventions - there we have none" (Woolf 1932: 234). But she is quick to point out that freedom in any meaningful sense involves more than being out from under the dictates of authority: "To enjoy freedom [...] we have to control ourselves. We must not squander our powers, squirting half the house in order to water a single rose-bud; we must train them, exactly and powerfully, here on the very spot." For such self-training the advice and suggestions of the experienced reader can, of course, be invaluable.

8. In Human Nature and Conduct (1922), Dewey stresses: "There is instinctive wisdom in the tendency of the young to ignore the limitations of the environment. Only thus can they discover their own power and learn the differences in different kinds of environing limitations. But this discovery when once made marks the birth of intelligence; and with its birth comes the responsibility of the mature to observe, to recall, to forecast" (MW 14: 118).

9. This expression and its use as part of the title for this essay is, of course, indebted to the title of one of Dewey's most important works, Art as Experience.

10. Our habits are what we primarily go on. "Experience is," Dewey asserts in a late manuscript, "no stream, even though the stream of feelings and ideas (that flows upon its surface is the part which philosophers love to traverse. Experience [however] includes the enduring banks of natural constitution and acquired habit as well as the stream" (LW 1:370).

11. Though I am quoting an instance of this remark as found in one of his published works, this was a point that John Smith was fond of making in informal conversation.

12. "For we do not, after all, simply have experience; we are," Patricia Hampl stresses, "entrusted with it. We must do something - make something - with it. A story, we sense, is the only possible habitation of the burden of our witnessing" (Hampl 1999: 18).

13. "The great public work of the instrumental philosophy," Hocking suggests in "Action and Certainty" (1929/1930), "has been to limber up the ways of knowing of this people [i.e., of the American people], to reduce fixed dogmas to working hypotheses fit for experiment; to the intellectually tradition, authority-seeking, heroworshipping American the courage of his own experience, As a people we do believe in the dignity of labor. [...] We must carry this belief over in the dignity of a laboring philosophy, arising out of and pertinent to existing crises, not to ancient ones" (LW 5: 463; emphasis added).

14. At the conclusion of "Circles," Emerson observes: "Nothing great was ever achieved without enthusiasm. The way of life is wonderful; it is by abandonment. The great moments of history are 
the facilities of performance through the strength or ideas, as the works of genius and religion. 'A man,' said Oliver Cromwell, 'never rises so high as when he knows not whither he is going.' Dreams and drunkenness, the use of opium and alcohol are the semblance and counterfeit of this oracular genius, and hence their dangerous attraction for men. For the like reason they ask the aid of wild passions, to ape in some manner these flames and generosities of the heart " (Emerson 1982: 238). In Human Nature and Conduct, Dewey highlights another facet of this, one concerning the orientation of children toward the world: "There is instinctive wisdom in the tendency of the young to ignore the limitations of the environment. Only thus can they discover their own power and learn the differences in different kinds of environing limitations" (MW 14: 118).

15. This is what John Keats advises in a letter and, moreover, what Dewey endorses in Art as Experience: in his famous phrase, this is "Negative Capability." In his far less famous explication, Keats means by this the capacity to live with "uncertainties, mysteries, doubts, without any irritable reaching after fact and reason" (quoted by Dewey in LW 10: 39). The resounding conclusion of this important chapter, the title of which in part is borrowed from Keats ("The Live Creature and "Ethereal Things"), is worth recalling here: "Ultimately there are but two philosophies. One of them accepts life and experience in all its uncertainties, mystery, doubt, and half-knowledge and turns that experience upon itself to deepen and intensify its own qualities to imagination and art. This is the philosophy of Shakespeare and Keats" (LW 10: 41). It is also the philosophy of Dewey and, arguably, the other pragmatists.

16. In Experience and Education, Dewey identifies a problem that he takes to be "new in the story of educa- tion: How shall the young become acquainted with the past in such a way that the acquaintance is a potent agent in appreciation of the living present?" (LW 13: 10). This is in effect a corollary derived from James's more general claim regarding human experience: nothing outside of the flux secures the issue of it.

17. In "One Current Religious Problem" (1936), a response to Percy Hughes's critique of A Common Faith and other writings by Dewey on religion, Dewey stresses: "About the importance of tradition - or, better, traditions - in effecting the desired organization I have no doubt. But I am high skeptical of all arguments that there is but one available tradition. We have at our disposal many traditions. There is the great tradition of autonomous literature, of music, of painting, of all the fine arts, in each of which, moreover, there are many significant traditions. There is the tradition of democracy; there is the tradition of experimental science, which if not thoroughly established is yet far from embryonic" (LW 11: 117). In The Public and Its Problems, Dewey insists: "The level of action fixed by embodied intelligence is always the important thing" (LW 2: 166). Intelligence is embodied in habits. It is also concretely embodied in the vast array of human artifacts without which the more refined dispositions of human agents would could never sustain themselves, let alone take deep enough root ever to flower.

18. A tradition is very often, if not always, an intergenerational struggle. Such an agon assumes a more central and intense form in some cultures than in others.

19. "The sweetest music," Emerson suggests, "is not the oratorio, but in the human voice when it speaks from its instant life, tones of tenderness, truth, or courage" (CW 2: 216; cf. Day 2000: 105).

20. "Somewhere being must," James insists, "iimediately breast nonentity. Why may not the advancing front of experience, carrying its immanent satisfactions and dissatisfactions, cut against the black inane as the luminous orb of the moon cuts the cærulean abyss? Why should anywhere the world be absolutely fixed and finsihed? And if reality genuinely grows, why may it not grow in these very determinations which here and now are made?" (MT: 222; emphasis added). "Our acts, our turning-places, where we seem to ourselves to make ourselves and grow, are," he asserts elsewhere, "the parts of the world to which we are closest, the parts of which our knowledge is the most intimate and complete. Why should we not take them at their face-value? Why may they not be the actual turning-places and growing-places which they seem to be, of the 
world - why not the workshop of being, where we catch fact in the making, so that nowhere may the world grow in any other kind of way than this?" (James 1978: 138).

21. There is no contradiction here. An extemporaneous performance can be a disciplined one, above all, because the disciplined attention of improvisational artists is a critical feature in any successful improvisation. The apparent "abandonment" of control is the suspension of dominant habits, for the sake of the more or less free play of suppressed ones but also the spontaneous promptings of inchoate impulses.

22. In a strong sense, an anarchist designates anyone who rejects laws as such; in a weaker sense, this term refers to an individual who rejects the state as an institution designed to enforce lawfulness. The kind of anarchist toward whom I am gesturing here does not reject forms as such, but rather the absolute authority of antecedently determined forms and, moreover, the fixation on form rather than preoccupation with processes of form-giving.

23. "There is," Dewey suggests in Experience and Education, "no discipline so severe as the discipline of experience subjected to the tests of intelligent development and direction" (LW 13: 90). Improvisation is voluntary, frequently joyful subjection to such immanent discipline - the discipline inherent in the demands, urgencies, and propensities of experience itself. Out of such discipline, creative intelligence alone is born. Rather than being an advocate of irrationalism or anti-intellectualism, Dewey was a champion of intelligence in this sense. No sensed more the vital role of creative intelligence "in the development and control of a living and moving experience" (LW 13: 60). Though in the text to which I am referring Dewey does not append this adjective to intelligence, there is little or no question that this is implicit in what he is advocating here.

24. "The release of some portion of the stock of impulses [always available to the live creature] is," Dewey notes in Human Nature and Conduct, "an opportunity, not an end. In its origin it is the product of chance; but it affords imagination and invention their chance. The moral correlate [also the artistic one] of liberated impulse is not immediate activity, but reflection upon the way in which to use impulse to renew disposition and reorganize habit" (MW 14: 117). But immediate activity might be both the initial phase of a reflective process and a promising gesture worthy of being repeated countless times and, in this process of reiteration, capable of being interrogated in diverse ways (think here of how a jazz musician will play the same lick over and over again, altering it ever so slightly, also often quite radically).

25. For the danger of egotism even in improvisation, see Garry Hagberg's "Jazz Improvisation and Ethical Interaction: A Sketch of the Connections." His example of the differences between the younger and older Stan Getz are especially instructive in this regard.

26. While this term will likely be taken as an allusion to Michel Foucault, and while this would not be a mistake, my use of it here refers primarily to what Sawyer identifies as "problemfinding" (Sawyer 2000: 153-54). For example, a “"problem-finding' painter is constantly searching for her or his visual problems while painting - improvising a painting rather than executing it" (Sawyer 2000: 153, emphasis added).

27. Here I am drawing heavily on the work of R. Keith Sawyer. See, in particular, Sawyer 2003. In a more extended treatment of this elusive topic, I would have to explain more fully what these terms designate. For the purpose of this paper, however, all I can do is refer my readers to the work of Sawyer. Nonetheless, I hope to return to this topic and, on that occasion, elaborate in my own way these salient features of the improvisational process.

28. An earlier but extremely illuminating articulation of this point is "Epistemological Realism: The Ubiquity of the Knowledge Relation" (MW 6).

29. While not all music is affectively charged, much is. Even those instances where little or no emotions are given sensuous form or expression in a piece of music, the textures of time as experienced are made available to us for contemplation or scrutiny. Those instances in which conflicts, tensions, and resolutions of an incredibly intricate character, with the characteristic 
emotion involvement invited by these instances, are, however, sensuous forms in which the textures of temporality are made most forcibly but also vividly available to us (see, e.g., Langer).

30. Here as well as elsewhere in this paper, I am using this word in the sense in which Wittgenstein and, following him, Cavell tend to use it.

31. Referring to Wittgenstein's later philosophy, Sabina Lovibond in Realism and Imagination in Ethics suggests: "The sickness which that philosophy sets out to treat (the 'bewitchment of our intelligence by means of language' [PI 1, \#109]) has its origins, he implies, in the incomplete acceptance of our embodied condition, and in our failure to acknowledge the significance of that condition for the reflective undersanding of such topics as meaning and rationality" (Lovibond 1983: 206), also of course such topics as action and time. Our incomplete acceptance of our embodied condition encompasses a failure to acknowledge that condition as temporal, without qualification.

\section{ABSTRACTS}

The characteristic form of human action is an extemporaneous performance or improvisational exertion. An ordinary conversation (what C. S. Peirce calls "a wonderfully perfect kind of signfunctioning" [EP 2: 391]) provides us with an extremely useful model for understanding other forms of "unrehearsed intellectual adventure" (Oakeshott 1991: 490), not least of all jazz improvisation. But since our inquiry into this range of considerations turns on appealing to our experience as improvisational actors in the overlapping situations of everyday life, this appeal itself needs to be considered. Accordingly, the appeal to experience is here interrogated with the aid of what pragmatists but also perfectionists such as Stanley Cavell say about it. What Cavell asserts regarding checking one's experience, as a way of rendering it trustworthy, is of the utmost critical importance for the present inquiry. After exploring what is entailed by an appeal to experience, when conjoined to what Cavell identifies as the task of checking one's experience, the author turns to our quotidian experience as improvisational actors and, ultimately, to the rather singular achievements of jazz improvisers. In doing so, he hopes to illuminate the inherently creative dimension of human action, wherever it unfolds.

\section{AUTHOR}

\section{VINCENT COLAPIETRO}

The Pennsylvania State University

vxc5[at]psu.edu 